were Choice in Dying and the Project on Dying in America, two nonprofit organizations that deal with end-of-life issues. According to a Choice in Dying spokesperson, "there is a bigger battle than physicianassisted suicide: the issue of educating the public about end-of-life treatment issues, which affect many more than those who support physician-assisted suicide. The Project on Death in America, which supports palliative care programs and is evaluating safeguards for any possible future implementation of physician-assisted suicide, urged that the Court not preempt public debate and legislative action by ruling prematurely on the constitutionality of physician-assisted suicide, but should instead allow states to serve as "laboratories of social experimentation." According to the Project's brief, until doctors more effectively treat pain, patients' desires for physician-assisted suicide cannot be considered autonomous. Financial pressures may likewise undermine a patient's voluntary choice of death. Furthermore, the mental competence of the dying may be compromised by confusion and depression, and therefore a decision may not truly be "free."

Fearful of being pushed down a slippery slope in their wheelchairs, the advocacy group for the disabled called "Not Dead Yet," demonstrated outside the Court during the hearings in addition to filing an amicus brief. Attorney Diane Coleman, cofounder of the group, says that physician-assisted suicide is "the most lethal form of discrimination, based on health status, [that] violates the Americans with Disabilities Act." According to Coleman, even if physician-assisted suicide were limited to the terminally ill, it would not protect people with disabilities, as both groups are routinely denied suicideprevention services. "Doctors and others routinely assume that disability is worse than death, because it represents a loss of dignity and control, and that people with disabilities have an undesirable quality of life - undesirable for whom?" she asks. "Of
Kevorkian's 40 'patients,' 28 were not terminally ill, but had various disabilities. As long as people with disabilities are treated as unwelcome and costly burdens on society, physician-assisted suicide is not voluntary, but is a forced 'choice."'

Although both sides attempted to build their cases on compassion for the dying and on philosophical cornerstones of bioethics (that is, autonomy, beneficence, nonmaleficence and justice), there may be no principled way to choose, as Robert Burt observed. The Supreme Court must weigh the rights and interests of the individual against those of the state, and their decision will undoubtedly reflect closely held personal and societal values that seem to be as ambivalent as they are strongly felt. After all, in the United States, where Jack Kevorkian is alternately indicted then exonerated, no physician has yet been convicted for helping a patient die.

VICKI BROWER New York, New York

\title{
A retirement plan for research chimps
}

Financial and ethical pressures weighing on the US government may give rise to a new kind of publicly funded retirement community: one that houses chimpanzees. Despite being infected with HIV and human hepatitis B virus, chimpanzees can live a projected 60 years in captivity. Current research practice prohibits killing chimpanzees used for viral research. As a result, the National Academy of Science is currently conducting a study on how much money the US National Institutes of Health (NIH) spends to house these chimps in animal facilities. Concurrently, a coalition of animal rights groups is pressuring Congress to earmark NIH funding for more creative housing solutions.

"Apparently the diseases we've given the chimpanzees do not shorten their lives," says Elizabeth Muchmore, formerly a consultant for the Laboratory of Experimental Medicine, Surgery in Primates (LEMSIP, Tuxedo, NY), a facility that pioneered the use of chimpanzees in hepatitis vaccine development. Muchmore disagrees with the ardent "no kill" stance, suggesting that sacrificing the animals and freezing their tissues for chronic infection studies is a more humane scenario than having the chimpanzees remain in isolated cages at animal research facilities for decades. But Jan Moore-Jankowski, founder of LEMSIP, feels that a policy of not killing the animals prevents their overuse. He points out that the per diem costs for housing chimpanzees now range from US $\$ 15$ to 30 , and this relatively high cost of long-term care deters researchers from using chimpanzees except when absolutely necessary.

In addition to the financial repercussions, the same genetic closeness between chimpanzees and humans that makes the animals useful for the viral research studies also stirs public sentiment. A recent proposal by an animal protection coalition suggests that the NIH set aside five percent of their primate research budget for retiring chimpanzees. They are hoping Congress will write this measure into the NIH funding Reauthorization Bill later this year. Participating organizations will also devote public donations to the maintenance of a new

facility.

Group housing of chimps could significantly reduce operating and handling costs. But it may be difficult to suddenly force chimpanzees into a group situation. Last year, in an effort to address concerns about introducing chimpanzees that have lived all

their lives in isolated cages into a group setting, Wallace Swett, director of Primarily Primates (San Antonio, Texas) accepted for retirement twelve chimpanzees ranging in age from 18 to 48 from the Buckshire Corporation (Perkasie, PA). Swett has been successful in getting the eight male chimps to coexist amiably. Even so, safety guidelines for handling during initial adjustment periods that may involve violent behavior need to be established to make this a widespread practice. Furthermore, the animals in the Buckshire colony are not infected with either HIV or hepatitis B, which would require special handling of chimps that did carry the viruses.

Is there any indication that Congress will provide the chimps with substantial retirement benefits? "Any movement on our part is very preliminary," says a Congressional spokesperson. According to J. Michael McGehee, lawyer for the animal protection coalition, a congressional appropriations committee is waiting for the results of the National Academy of Sciences study before making any decisions.

BARBARA NASTO New York, New York 